\title{
PENGARUH KEBERADAAN PT. HUTAN KETAPANG INDUSTRI TERHADAP PENDAPATAN RUMAH TANGGA MASYARAKAT DI KECAMATAN KENDAWANGAN KABUPATEN KETAPANG
}

\author{
AKHMAD YAMANI ${ }^{1)}$, NOVIRA KUSRINI ${ }^{2)}$, KOMARIYATI ${ }^{2)}$ \\ 1) Alumni Magister Manajemen Agribisnis Fakultas Pertanian Universitas \\ Tanjungpura Pontianak. \\ 2) Staf Pengajar Fakultas Pertanian Universitas Tanjungpura Pontianak
}

\begin{abstract}
The method used in this research is quantitative research besifat. The research is descriptive quantitative research. Kuantiitatif descriptive study is essentially a research method or approach a case study (case study). This study focuses intensively on the object that is the effect of the existence of PT. Ketapang Forest Industry tehadap Household Income in Rural Communities Kedondong. The purpose of this study was to (a). Knowing the influence of the existence of PT. Ketapang Forest Industry on Household Income Communities in the District Kendawangan Ketapang. (B). Knowing how much influence the presence of PT. Ketapang Forest Industry on Household Income Communities in the District Kendawangan Ketapang. RESULTS: (1) .Hutan Industrial Plant PT. Ketapang Forest Industries give effect to the increase in revenue. Average Household Income Communities bigger than the Rural Household Income Kendawangan Right. That is evidenced by the average income of the respondents in the two areas of research that Kedondong village and the village of Kanan Kendawangan include major revenue, and revenue side of the family. In the Village area Kedondong which is the village where PT. Ketapang forest industry has a monthly average income of Rp. 9,408,125. While Countryside Kendawangan Right who do not are planted in the construction of PT. Ketapang forest industry has a monthly average income of Rp. 7,360,667. So that the average monthly income of the village with the existence of PT. Ketapang Forest Industries and Village without the existence of PT. Ketapang Forest Industry there is a difference or a difference of Rp. 2,047,458. So the conclusion from the findings that the Household Income Communities in Rural Kedondong is high because melilbihi Minimum Wages average of return that is equal Rp.1.800.000. (2) Industrial Plantation Forest .Aktifitas provide considerable influence on the improvement of Household Income in Rural Communities Kedondong Kendawangan District of Ketapang.

Keywords: Effect, PT. Ketapang Forest Industry, Household Income Society
\end{abstract}

\section{PENDAHULUAN}

Keberadaan Hutan Tanaman Industri yang dikelola oleh PT. Hutan Ketapang Industri, diharapkan dapat memberikan dampak positif bagi masyarakat sekitar, antara lain:

1) Dapat membuka kesempatan berusaha masyarakat

2) Diharapkan dapat berperan dalam meningkatkan kesejahteraan masyarakat dari segi pendapatan rumah tangga. 
Keberadaan HTI diharapkan dapat mengoptimalkan pemanfaatan sumber daya hutan Indonesia guna kemakmuran rakyat, dengan tetap memperhatikan kelestarian lingkungan. Sejalan dengan hal tersebut telah diatur di dalam Peraturan Menteri Kehutanan Nomor : P.62/Menhut-II/2008 tangal 6 November 2008 tentang Rencana Kerja Tahunan Usaha Pemanfaatan Hasil Hutan Kayu Pada Hutan Tanaman, yang mengatur bahwa setiap perusahaan wajib untuk melaksanakan kegiatan kelestarian fungsi sosial terhadap masyarakat dengan mengadakan kegiatan pembinaan dan pemberdayaaan bagi masyarakat di dalam dan disekitar hutan.

\section{METODE PENELITIAN}

\section{Metode Penelitian}

Penelitian ini adalah penelitian yang besifat kuantitatif. Penelitian yang digunakan yaitu penelitian kuantitatif deskriptif. Penelitian kuantiitatif deskriptif adalah berupa penelitian dengan metode atau pendekatan studi kasus (case study). Penelitian ini memusatkan diri secara intensif pada satu obyek tertentu yang mempelajarinya sebagai suatu kasus. Data studi kasus dapat diperoleh dari semua pihak yang bersangkutan, dengan kata lain dalam studi ini dikumpulkan dari berbagai sumber.

Secara ringkasnya yang membedakan metode studi kasus dengan metode penelitian kualitatif lainnya adalah kedalaman analisisnya pada kasus yang lebih spesifik baik kejadian maupun fenomena tertentu.

\section{a. Pemilihan Lokasi dan Periodesasi Penelitian}

Lokasi penelitian dilakukan di wilayah Desa Kedondong dan Desa Kendawangan Kanan Kecamatan Kendawangan Kabupaten Ketapang, masyarakat yang bermukim di kawasan Hutan Tanaman Industri Hutan Ketapang Industri Khususnya pada Desa Kedondong merupakan desa yang berada di kawasan Hutan Tanaman Industri, sedangkan Desa Kendawangan Kanan merupakan Desa yang tidak berada di kawasan Hutan Tanaman Industri.

\section{b. Populasi dan Metode Pengambilan Sampel}

Populasi adalah wilayah generalisasi yang terdiri atas objek atau subjek yang mempunyai kualitas dan karateristik tertentu yang ditetapkan penelitian untuk dipelajari dan kemudian ditarik kesimpulannya (Sugiono, 1994). Sedangkan sampel adalah sebagian dari jumlah dan karateristik yang dimiliki populasi. Sampel yang baik adalah sampel yang representatif mewakili populasi, jumlah sampel yang akan diambil sebagai sumber data tergantung pada tingkat kepercayaan yang dikehendaki. Dalam penelitian yang dilakukan terdapat populasi sejumlah 320 Kepala Keluarga (KK) Desa Kedondong dan 300 Kepala Keluarga (KK) Desa Kendawangan Kanan sebagai Desa yang tidak terkena dampak Hutan Tanaman Industri.

Untuk menentukan ukuran sampel dari populasi yang termasuk dalam batasan lokasi penelitian menggunakan pendapat Slovin yang dirumuskan sebagai berikut (Husein Umar, 2001).

$$
n=\frac{N}{1+N e^{2}}
$$




\section{Dimana :}

$\begin{array}{ll}\mathrm{n} & =\text { Ukuran sampel } \\ \mathrm{N} & =\text { Ukuran populasi } \\ \mathrm{e} & =\text { Persen kelonggaran ketidaktelitian karena kesalahan yang masih }\end{array}$ dapat ditolerir atau diinginkan, dalam penelitian ini digunakan $10 \%$ Maka perhitungan jumlah sampel di Desa Kedondong yang digunakan yaitu:

$$
\begin{aligned}
& n=\frac{320}{1+320(0,1)^{2}} \\
& n=\frac{320}{4,2} \\
& \mathrm{n}=76,19 \text { dibulatkan menjadi } 80
\end{aligned}
$$

Hasil perhitungan dengan diketahui jumlah populasi $320 \mathrm{KK}$ didapatkan hasil sejumlah 80 sampel KK. Untuk mendapatkan sampel pada tiap-tiap RT secara proporsional dilakukan dengan cara proporsional sampling yaitu pengambilan sampel dengan memberikan proporsi menurut jumlah populasi pada masing-masing RT yang ada di Desa Kedondong. Adapun penarikan sampel pada masing-masing RT dapat dilihat pada tabel 2.1 berikut :

Tabel 2.1 Penarikan Responden Masing-Masing RT di Desa Kedondong

\begin{tabular}{ccccccc}
\hline No & RT/RW & $\begin{array}{c}\text { Kepala } \\
\text { Keluarga } \\
(\text { KK) }\end{array}$ & \% & $\begin{array}{c}\text { Jumlah } \\
\text { Sampel }\end{array}$ & $\begin{array}{c}\text { \% } \\
\text { Sampel }\end{array}$ & $\begin{array}{c}\text { Proporsi } \\
\text { Sampel }\end{array}$ \\
\hline 1. & $01 / \mathrm{I}$ & 65 & 0,20 & 80 & 16,25 & 16 \\
2. & $02 / \mathrm{I}$ & 65 & 0,20 & 80 & 16,25 & 16 \\
3. & $03 / \mathrm{II}$ & 62 & 0,19 & 80 & 15,50 & 16 \\
4. & $04 / \mathrm{II}$ & 60 & 0,19 & 80 & 15,00 & 15 \\
5. & $05 / \mathrm{III}$ & 68 & 0,21 & 80 & 17,00 & 17 \\
\hline & Total & $\mathbf{3 2 0}$ & $\mathbf{1 , 0 0}$ & & $\mathbf{1 0 0}$ & $\mathbf{8 0}$ \\
\hline
\end{tabular}

Sumber : Analisis Data Primer, 2015

Sampel yang berjumlah $80 \mathrm{KK}$ tersebut di atas digunakan untuk pengambilan data primer untuk mengukur variabel Pendapatan Rumah Tangga Masyarakat. Berikut perhitungan jumlah sampel di Desa Kendawangan Kanan yang digunakan yaitu :

$$
\begin{aligned}
& n=\frac{300}{1+300(0,1)^{2}} \\
& n=\frac{300}{4,0} \\
& \mathrm{n}=75
\end{aligned}
$$

Adapun penarikan sampel pada masing-masing RT di Desa Kendawangan Kanan dapat dilihat pada Tabel 2.2 berikut : 
Tabel 2.2 Penarikan Responden Masing-Masing RT di Desa Kendawangan Kanan

\begin{tabular}{ccccccc}
\hline No & RT/RW & $\begin{array}{c}\text { Kepala Keluarga } \\
(\text { KK) }\end{array}$ & $\%$ & $\begin{array}{c}\text { Jumlah } \\
\text { Sampel }\end{array}$ & $\begin{array}{c}\% \\
\text { Sampel }\end{array}$ & $\begin{array}{c}\text { Proporsi } \\
\text { Sampel }\end{array}$ \\
\hline 1. & $01 / \mathrm{I}$ & 60 & 0,20 & 75 & 15,00 & 15 \\
2. & $02 / \mathrm{I}$ & 58 & 0,21 & 75 & 15,75 & 16 \\
3. & $03 / \mathrm{II}$ & 60 & 0,19 & 75 & 14,25 & 14 \\
4. & $04 / \mathrm{II}$ & 60 & 0,19 & 75 & 14,25 & 14 \\
5. & $05 / \mathrm{III}$ & 62 & 0,21 & 75 & 15,75 & 16 \\
\hline & Total & 300 & 1,00 & & 100,00 & 75 \\
\hline
\end{tabular}

Sumber : Analisis Data Primer, 2015

Sampel yang berjumlah $75 \mathrm{KK}$ tersebut di atas digunakan untuk pengambilan data primer untuk mengukur variable Pendapatan Rumah Tangga Masyarakat.

\section{c. Sumber dan Metode Pengumpulan Data}

\section{Variabel Penelitian}

Variabel yang digunakan dalam penelitian ini adalah pendapatan rumah tangga masyarakat meliputi pendapatan pokok suami, istri, keluarga lain seperti anak, keponakan dan saudara yang bermukim dalam keluarga. Selain itu variable juga menggunakan pekerjaan sampingan yaitu buruh tani, pedagang, usaha warung, makan, usaha kios BBM dan sebagai tukang bangunan.

\section{Analisis Data}

Uji t- test yang digunakan adalah uji t rata-rata tidak berpasangan. Untuk menguji Pendapatan Rumah Tangga Masyarakat Desa Kedondong digunakan rumus ( Suprapto J, 2009) :

$$
\begin{aligned}
& t_{h u}=\frac{X_{1}-X_{2}}{\sqrt{\left[\frac{\left(n_{1}-1\right) S_{1}^{2} \mp\left(n_{2}-1\right) S_{L}^{2}}{n_{1}+n_{i}-2}\right] x\left[\frac{1}{n_{1}}+\frac{1}{n_{2}}\right]}} \\
& S=\sqrt{\frac{\sum_{l=1}^{n} x_{1}^{2}-\frac{\left(\sum_{l-1}^{n} x_{1}\right)^{2}}{n}}{n-1}}
\end{aligned}
$$

Keterangan :

$\mathrm{X}_{1}=$ Sampel 1

$\mathrm{X}_{2}=$ Sampel 2

$\mathrm{S}_{1}=$ simpangan baku sampel $1 \quad \mathrm{~S}_{2}=$ Simpangan baku sampel 2

$\mathrm{n} 1$ = banyaknya data sampel $1 \quad \mathrm{n} 2$ = banyaknya data sampel 2

Sampel 1 = Pendapatan Rumah Tangga Masyarakat Desa Kedondong

Sampel 2 = Pendapatan Rumah Tangga Masyarakat Desa Kendawangan Kanan

Menurut Supranto J (2009), penentu tingkat nyata ( Significant Level) adalah menentukan peluang untuk menolak $\mathrm{H}_{0}$ padahal $\mathrm{H}_{0}$ itu benar. Suatu peluang berada pada kisaran 0 dan 1 . Jika 0 dinyatakan tidak mungkin terjadi sedangkan 1 dinyatakan pasti terjadi. Jika kita mengatakan bahwa peluang untuk menolak $\mathrm{H}_{0}$ padahal $\mathrm{H}_{0}$ itu benar adalah 5\% maka nilai $\alpha=0,05$.

Menghitung $t_{\text {tabel }}$ adalah dengan mengetahui taraf signifikan $\alpha=0,05$, kemudian dicari nilai $t_{\text {tabel }}$ pada tabel distribusi $-t$ dengan ketentuan $d b=n-1$, sehingga $t_{\text {tabel }}(a, d b)$. 


\section{HASIL DAN PEMBAHASAN}

Hasil dan pembahasan yang diperoleh untuk menjawab rumusan masalah penelitian disesuaikan berdasarkan alur prosedur metode penelitian adalah sebagai berikut: Pendapatan utama rumah rangga responden berasal dari berbagai sumber pendapatan, dimana masing-masing sumber berperan penting untuk memenuhi kebutuhan rumah tangga masyarakat. Sumber-sumber pendapatan utama rumah tangga responden berasal dari pendapatan On Farm, Off Farm dan Non Farm.

Tabel 3.1 Jumlah Rata-Rata Pendapatan Rumah Tangga Utama Responden di Desa Kedondong dan Desa Kendawangan Kanan Perbulan

\begin{tabular}{|c|c|c|c|c|c|c|c|}
\hline $\begin{array}{c}\text { Jenis Pekerjaan } \\
\text { Utama }\end{array}$ & $\begin{array}{c}\text { Jumlah } \\
\text { Tenaga } \\
\text { Kerja }\end{array}$ & $\begin{array}{c}\text { Total } \\
\text { Pendapatan } \\
\text { Per Bulan } \\
(\mathbf{R p}) \\
\end{array}$ & $\begin{array}{c}\text { Rata-rata } \\
\text { Pendapatan } \\
\text { Perbulan } \\
(\mathbf{R p}) \\
\end{array}$ & $\begin{array}{c}\text { Jenis Pekerjaan } \\
\text { Utama }\end{array}$ & $\begin{array}{c}\text { Jumlah } \\
\text { Tenaga } \\
\text { Kerja }\end{array}$ & $\begin{array}{c}\text { Total } \\
\text { Pendapatan } \\
\text { Per Bulan } \\
\text { (Rp) } \\
\end{array}$ & $\begin{array}{c}\text { Rata-rata } \\
\text { Pendapata } \\
\text { n Perbulan } \\
\text { (Rp) }\end{array}$ \\
\hline \multicolumn{4}{|c|}{ Desa Kedondong } & \multicolumn{4}{|c|}{ Desa Kendawangan Kanan } \\
\hline \multicolumn{4}{|c|}{ ON FARM } & \multicolumn{4}{|c|}{ ON FARM } \\
\hline Petani Sayur & 4 & 20.100 .000 & 5.025 .000 & Petani Sayur & 6 & 20.000 .000 & 1.333 .333 \\
\hline Petani Padi & 5 & 41.700 .000 & 8.340 .000 & Petani Padi & 3 & 17.000 .000 & 5.666 .667 \\
\hline Petani Palawija & 3 & 26.000 .000 & 8.666 .667 & Petani Palawija & 4 & 17.000 .000 & 4.250 .000 \\
\hline \multicolumn{4}{|c|}{ OFF FARM } & \multicolumn{4}{|c|}{ OFF FARM } \\
\hline Buruh PT. HKI & 20 & 56.000 .000 & 2.800 .000 & Buruh Tani & 8 & 10.600 .000 & 1.325 .000 \\
\hline $\begin{array}{l}\text { Buruh Harian } \\
\text { Lepas PT.HKI }\end{array}$ & 17 & 35.600 .000 & 2.094 .118 & Peternakan & 5 & 57.000 .000 & 11.400 .000 \\
\hline Mandor PT.HKI & 8 & 36.000 .000 & 4.500 .000 & Nelayan & 25 & 61.800 .000 & 2.472 .000 \\
\hline Krani PT.HKI & 5 & 16.000 .000 & 3.200 .000 & Pedagang Ikan & 7 & 16.250 .000 & 2.321 .429 \\
\hline Pengrajin Sagu & 2 & 8.000 .000 & 4.000 .000 & & & & \\
\hline \multicolumn{4}{|c|}{ NON FARM } & \multicolumn{4}{|c|}{ NON FARM } \\
\hline $\begin{array}{l}\text { Pedagang } \\
\text { Sembako }\end{array}$ & 4 & 195.000 .000 & 48.750 .000 & $\begin{array}{l}\text { Pedagang } \\
\text { Sembako }\end{array}$ & 5 & 180.000 .000 & 36.000 .000 \\
\hline Pengusaha Mebel & 1 & 50.000 .000 & 50.000 .000 & Pengusaha Mebel & 1 & 45.000 .000 & 45.000 .000 \\
\hline Penjahit & 1 & 3.500 .000 & 3.500 .000 & Penjahit & 2 & 6.000 .000 & 3.000 .000 \\
\hline Aparatur Desa & 4 & 10.000 .000 & 2.500 .000 & Aparatur Desa & 2 & 5.000 .000 & 2.500 .000 \\
\hline PNS & 3 & 9.750 .000 & 3.250 .000 & PNS & 4 & 12.600 .000 & 3.150 .000 \\
\hline Tukang Bangunan & 3 & 10.500 .000 & 3.500 .000 & Tukang Bangunan & 3 & 9.000 .000 & 3.000 .000 \\
\hline Jumlah Total & 80 & 518.150 .000 & 150.125 .785 & Jumlah Total & 75 & 457.250.000 & 121.418.429 \\
\hline
\end{tabular}

Sumber : Analaisis Data Primer, 2015

Pada Tabel 3.1 menunjukan bahwa pendapatan utama rumah tangga responden Desa Kedondong dengan total pendapatan sebesar Rp. 518.150.000 perbulan dengan rata-rata sebesar Rp.150.125.785 perbulan. Sedangkan pada Desa Kendawangan Kanan menunjukan bahwa pendapatan utama rumah tangga responden dengan total pendapatan sebesar Rp.457.250.000 perbulan dengan ratarata pendapatan utama sebesar Rp.121.418.429 perbulan. Sehingga dapat disimpulkan bahwa pendapatan rumah tangga masyarakat pada Desa yang teletak di wilayah PT. Hutan Ketapang Industri lebih besar dari pendapatan di Desa yang tidak berada di wilayah PT. Hutan Ketapang Industri dengan selisih pendapatan sebesar Rp. 518.150.000 - Rp.457.250.000 = Rp.60.900.000 perbulan. Pendapatan Rumah Tangga utama responden lebih dominan pada sumber pendapatan dari PT. Hutan Ketapang Industri yaitu buruh perkebunan dan pekerja tetap di PT. Hutan Ketapang Industri sebanyak 20 responden dengan jumlah total pendapatan perbulan sebesar Rp.56.000.000 dan rata-rata pendapatan responden sebesar Rp.2.800.000 perbulan. Sedangkan di Desa Kendawangan Kanan pendapatan utama lebih didominasi oleh pendapatan dari hasil pekerjaan sebagai nelayan sebanyak 25 responden dari total jumlah responden 75 dengan total pendapatan perbulan sebesar Rp.61.800.000 dengan rata-rata pendapatan sebesar Rp.2.472.000 perbulan. 
1. Jumlah Responden Berdasarkan Pekerjaan Sampingan

a. Jumlah Responden Berdasarkan Pekerjaan Sampingan

Dari jumlah total responden Desa Kedondong dan Desa Kendawangan Kanan bahwa dapat disimpulkan jenis pekerjaan sampingan yang paling dominan di Desa Kedondong adalah petani karet sebesar 17 responden atau sekitar 20 persen dari total responden sebanyak 80 orang. Sedangkan pekerjaan sampingan yang paling dominan di Desa Kendawangan Kanan adalah kios BBM sebanyak 15 responden atau sekitar 20 persen dari total responden sebanyak 75 orang. Agar lebih jelas dapat dilihat pada tabel 3.2 berikut:

Tabel 3.2 Jumlah Responden Berdasarkan Pekerjaan Sampingan

\begin{tabular}{|c|c|c|c|c|c|}
\hline \multicolumn{3}{|c|}{ Desa Kedondong } & \multicolumn{3}{|c|}{ Desa Kendawangan Kanan } \\
\hline & Jumlah & & & Jumlah & \\
\hline Jenis Pekerjaan & $\begin{array}{c}\text { Respon } \\
\text { den }\end{array}$ & $\%$ & Jenis Pekerjaan & $\underset{n}{\text { Responde }}$ & $\%$ \\
\hline \multicolumn{6}{|c|}{ On Farm } \\
\hline Petani karet & 17 & 20,00 & Petani Karet & 6 & 8,00 \\
\hline Petani Sawit & 8 & 10,67 & & & \\
\hline \multicolumn{6}{|c|}{ Off Farm } \\
\hline Peternakan & 5 & 6,67 & Buruh Harian Lepas & 14 & 18,67 \\
\hline \multicolumn{6}{|c|}{ Non Farm } \\
\hline Kios BBM & 11 & 16,00 & Warung Makan & 8 & 10,67 \\
\hline Tukang Batu & 6 & 9,33 & Kios BBM & 15 & 20,00 \\
\hline Warung Es & 10 & 14,67 & Tukang Batu & 5 & 6,67 \\
\hline Warung Makan & 4 & 5,33 & Penarik Motor Air & 3 & 4,00 \\
\hline $\begin{array}{l}\text { Tidak Memiliki } \\
\text { Sampingan }\end{array}$ & 19 & 24,00 & Tidak Memiliki Sampingan & 24 & 32,00 \\
\hline Total & 80 & 100,00 & Total & 75 & 100,00 \\
\hline
\end{tabular}

Sumber : Analisis data Primer, 2015

b. Jumlah Rata-Rata Perbulan Pendapatan Sampingan Rumah Tangga

Tabel 3.3 Jumlah Pendapatan Rumah Tangga Sampingan Responden di Desa Kedondong dan Desa Kendawangan Kanan

\begin{tabular}{|c|c|c|c|c|c|c|c|}
\hline $\begin{array}{c}\text { Jenis } \\
\text { Pekerjaan } \\
\text { Sampingan }\end{array}$ & $\begin{array}{c}\text { Jumlah } \\
\text { Tenaga } \\
\text { Kerja }\end{array}$ & $\begin{array}{c}\text { Total } \\
\text { Pendapatan } \\
\text { Sampingan Per } \\
\text { Bulan (Rp) }\end{array}$ & $\begin{array}{c}\text { Rata-rata } \\
\text { Pendapatan } \\
\text { Sampingan } \\
\text { Perbulan } \\
\text { (Rp) }\end{array}$ & $\begin{array}{c}\text { Jenis } \\
\text { Pekerjaan } \\
\text { Sampingan }\end{array}$ & $\begin{array}{c}\text { Jumlah } \\
\text { Tenaga } \\
\text { Kerja }\end{array}$ & $\begin{array}{c}\text { Total } \\
\text { Pendapata } \\
\mathbf{n} \\
\text { Sampingan } \\
\text { Per Bulan } \\
\text { (Rp) } \\
\end{array}$ & $\begin{array}{c}\text { Rata-rata } \\
\text { Pendapata } \\
\mathbf{n} \\
\text { Sampingan } \\
\text { Perbulan } \\
\text { (Rp) }\end{array}$ \\
\hline \multicolumn{4}{|c|}{ Desa Kedondong } & \multicolumn{4}{|c|}{ Desa Kendawangan Kanan } \\
\hline \multicolumn{4}{|c|}{ ON FARM } & \multicolumn{4}{|c|}{ ON FARM } \\
\hline $\begin{array}{l}\text { Petani karet } \\
\text { Petani Sawit }\end{array}$ & $\begin{array}{c}17 \\
8\end{array}$ & $\begin{array}{l}46.600 .000 \\
21.000 .000\end{array}$ & $\begin{array}{l}2.741 .176 \\
2.625 .000\end{array}$ & Petani Karet & 6 & 8.300 .000 & 1.383 .333 \\
\hline \multicolumn{4}{|c|}{ OFF FARM } & \multicolumn{4}{|c|}{ OFF FARM } \\
\hline Peternakan & 5 & 90.000 .000 & 18.000 .000 & $\begin{array}{l}\text { Buruh Harian } \\
\text { Lepas }\end{array}$ & 14 & 16.750 .000 & 1.196 .429 \\
\hline \multicolumn{4}{|c|}{ NON FARM } & \multicolumn{4}{|c|}{ NON FARM } \\
\hline Kios BBM & 11 & 23.050 .000 & 2.095 .456 & $\begin{array}{l}\text { Warung } \\
\text { Makan }\end{array}$ & 8 & 84.500 .000 & 10.562 .500 \\
\hline Tukang Batu & 6 & 13.600 .000 & 2.266 .667 & Kios BBM & 15 & 18.700 .000 & 1.246 .667 \\
\hline Warung Es & 10 & 9.950 .000 & 995.000 & Tukang Batu & 5 & 17.200 .000 & 3.440 .000 \\
\hline $\begin{array}{l}\text { Warung } \\
\text { Makan }\end{array}$ & 4 & 46.500 .000 & 11.625 .000 & $\begin{array}{l}\text { Penarik } \\
\text { Motor Air }\end{array}$ & 3 & 2.900 .000 & 966.667 \\
\hline Total & 61 & 250.700 .000 & 40.348.299 & Total & 51 & 148.350.000 & 18.795 .596 \\
\hline
\end{tabular}

Sumber : Analisis Data Primer, 2015

\section{A. Analisis Pendapatan Rumah Tangga Masyarakat di Dua Wilayah Penelitian}

Penelitian ini bertujuan untuk mengetahui pengaruh keberadaan PT. Hutan Ketapang Industri terhadap pendapatan rumah tangga masyarakat 
Desa Kedondong, maka untuk mengetahui pengaruh tersebut peneliti membandingkan pendapatan rumah tangga antara Desa Kedondong dan Desa Kendawangan Kanan. Perbandingan dua wilayah tersebut akan di analisis dengan menggunakan uji $\mathrm{t}$ dalam program SPSS.

Uji t dilakukan untuk mengetahui perbandingan rata-rata pendapatan rumah tangga masyarakat antara dua wilayah yang tidak saling berkaitan. Uji ini dipergunakan untuk menguji kebenaran atau kepalsuan hipotesis yang telah dibuat. Berikut hipotesisnya:

$\begin{array}{ll}\text { Ho } & :\left(X_{1} \leq X_{2}\right) \\ \text { Ha } & :\left(X_{1}>X_{2}\right)\end{array}$

Keterangan :

Ho : diduga pendapatan rumah tangga masyarakat Desa Kedondong lebih kecil atau sama dengan pendapatan rumah tangga masyarakat Desa Kendawangan Kanan.

$\mathrm{Ha}$ : diduga pendapatan rumah tangga masyarakat Desa Kedondong lebih besar dari pendapatan rumah tangga masyarakat Desa Kendawanan Kanan.

Jika t-hitung > t-tabel, maka pendapatan rumah tangga masyarakat Desa Kedondong lebih besar dari pada pendapatan rumah tangga masyarakat Desa Kendawangan Kanan. Maka Ho ditolak dan Ha diterima.

Jika t-hitung $\leq \mathrm{t}$-tabel, maka pendapatan rumah tangga masyarakat Desa Kedondong lebih kecil atau sama dengan pendapatan rumah tangga masyarakat Desa Kendawangan Kanan. Maka Ho diterima dan Ha ditolak.

Berikut t-tabel:

Diketahui jumlah responden (n) $155 \mathrm{kk}$, taraf signifikan $\alpha=0,05$

$$
\begin{aligned}
& \mathrm{db} \quad=\mathrm{n}-1 \quad \text { thabel }(\alpha, \mathrm{db})=\mathrm{t}_{\text {tabel }}(0,05,154) \\
& =155-1 \quad \mathrm{t}_{\text {tabel }} \quad=2,000(\text { pada tabel distribusi }-\mathrm{t}) \\
& =154
\end{aligned}
$$

Untuk mengetahui t-hitung dapat dilihat dari hasil output uji t yang

\begin{tabular}{|c|c|c|c|c|c|c|c|c|c|c|}
\hline & & \multicolumn{3}{|c|}{$\begin{array}{c}\text { Levene's Test } \\
\text { for Equality of } \\
\text { Variances }\end{array}$} & \multicolumn{6}{|c|}{ t-test for Equality of Means } \\
\hline & & \multirow[t]{2}{*}{$\mathrm{F}$} & \multirow[t]{2}{*}{ Sig. } & \multirow[t]{2}{*}{$\mathrm{t}$} & \multirow[t]{2}{*}{ df } & \multirow[t]{2}{*}{$\begin{array}{c}\text { Sig. } \\
\text { (2-tailed) }\end{array}$} & \multirow[t]{2}{*}{$\begin{array}{l}\text { Mean } \\
\text { Differ } \\
\text { ence }\end{array}$} & \multirow{2}{*}{$\begin{array}{l}\text { Std. } \\
\text { Error } \\
\text { Differ } \\
\text { ence } \\
\end{array}$} & \multicolumn{2}{|c|}{$\begin{array}{l}\text { 95\% Confidence } \\
\text { Interval of the } \\
\text { Difference }\end{array}$} \\
\hline & & & & & & & & & Lower & Upper \\
\hline \multirow{2}{*}{$\begin{array}{l}\text { Pend } \\
\text { apata } \\
\mathrm{n}\end{array}$} & $\begin{array}{l}\text { Equal } \\
\text { variances } \\
\text { assumed }\end{array}$ & 10,700 & ,001 & 4,061 & 153 & ,000 & $\begin{array}{c}40409 \\
4\end{array}$ & 99509 & $\begin{array}{c}20750 \\
5\end{array}$ & 600683 \\
\hline & $\begin{array}{l}\text { Equal } \\
\text { variances not } \\
\text { assumed }\end{array}$ & & & 4,121 & $\begin{array}{l}132,11 \\
0\end{array}$ &, 000 & $\begin{array}{c}40409 \\
4\end{array}$ & 98046 & $\begin{array}{c}21015 \\
0\end{array}$ & 598038 \\
\hline
\end{tabular}
menggunakan program aplikasi SPSS 22.

Tabel 3.4 Uji t Sampel Tidak Berpasangan

Sumber : Analisis Data Primer tahun 2015

Dari hasil tabel output diatas dapat diketahui nilai t-hitung adalah sebesar 4,061 Karena t-hitung $(4,061)>$ t-tabel $(2,000)$ maka dapat disimpulkan bahwa pendapatan rumah tangga masyarakat Desa Kedondong lebih besar dari pada pendapatan rumah tangga masyarakat Desa Kendawangan Kanan. Maka Ho ditolak dan Ha diterima. 
Berdasarkan hasil analisis menggunakan uji t satu sampel, pendapatan rumah tangga masyarakat di Desa Kedondong lebih tinggi dari pendapatan rumah tangga masyarakat di Desa Kendawangan Kanan. Itu disebabkan Desa Kedondong merupakan Desa yang teletak di wilayah pembangunan PT. Hutan Ketapang Industri. Pendapatan Rumah Tangga Masyarakat Desa Kedondong lebih besar yaitu dengan perolehan pendapatan perbulan mencapai Rp.717,350,000 dengan rata-rata pendapatan sebesar Rp.10,103,521 perbulan. Sedangkan di Desa Kendawangan Kanan memperoleh penghasilan sebesar Rp.611,050,000 dengan total rata-rata penghasilan sebesar Rp.8,147,333 perbulan. Sehingga dapat kita tarik kesimpulan bahwa terdapat perbedaan antara pendapatan yang berada di wilayah PT. Hutang Ketapang Industri dengan Desa yang berada di luar wilayah PT. Hutan Ketapang Industri.

Dari hasil rata-rata total pendapatan dapat di kalkulasikan sebagai berikut Desa Kedondong memperoleh Rp.10.103.521 dan Desa Kendawangan Kanan sebesar Rp.8.147.333 sehingga terdapat perbedaan atau selisih antara Desa Kedondong dan Desa Kendawangan Kanan sebesar Rp.1.956.188. Jadi kesimpulannya adalah keberadaan PT. Hutan Ketapang Industri mempengaruhi Pendapatan Rumah Tangga Masyarakat di Desa Kedondong karena kita ketahui bahwa Pendapatan Rumah Tangga Masyarakat di Desa Kedondong lebih besar dari Pendapatan Rumah Tangga Desa Kendawangan Kanan.

B. Perbedaan Pendapatan Rumah Tangga Masyarakat di dua Wilayah Penelitian

Pendapatan dari antara wilayah Desa Kedondong dan Desa Kendawangan Kanan sangatlah berbeda. Tepatnya perbedaan pada Pendapatan Rumah Tangga Masyarakat Desa Kedondong dengan pendapatan Desa Kendawangan Kanan. Pendapatan Rumah Tangga Masyarakat pada responden terbagi dari tiga yaitu pendapatan utama, pendapatan sampingan dan pendapatan anggota keluarga. Desa Kedondong pendapatan utama meliputi pendapatan on-farm, off farm dan non farm sedangkan pendapatan keluaraga meliputi pendapatan yang diperoleh dari hasil pendapatan utama keluarga, sedangkan pendapatan sampingan meliputi pendapatan berdagang, tukang bangunan, warung makan, kios BBM dan buruh tani.

Tabel 3.5 Pendapatan Rata-Rata Responden di Desa Kedondong dan Desa Kendawangan Kanan Perbulan

\begin{tabular}{lllcc}
\hline Wilayah / Desa & $\begin{array}{c}\text { Pendapatan } \\
\text { Utama (Rp) }\end{array}$ & $\begin{array}{c}\text { Pendapatan } \\
\text { Sampingan } \\
(\mathbf{R p )}\end{array}$ & $\begin{array}{c}\text { Pendapatan } \\
\text { Anggota } \\
\text { Keluarga } \\
(\mathbf{R p )}\end{array}$ & $\begin{array}{c}\text { Rata- rata } \\
\text { Pendapatan } \\
\text { perbulan } \\
(\mathbf{R p )}\end{array}$ \\
\hline $\begin{array}{l}\text { Kedondong (HTI) } \\
\text { Kendawangan }\end{array}$ & $6,476,875$ & $4,250,000$ & $3,544,118$ & $9,408,125$ \\
Kanan (No HTI) & $5,310,000$ & $1,484,884$ & $7,495,833$ & $7,360,667$ \\
\hline
\end{tabular}

Sumber : Data Primer Tahun 2015

Berdasarkan tabel 3.5 dapat di jelaskan sebagai berikut, pendapatan rata-rata responden di dua wilayah penelitian yaitu Desa Kedondong dan 
Desa Kendawangan Kanan meliputi pendapatan utama, sampingan dan pendapatan anggota keluarga. Di wilayah Desa Kedondong yang merupakan Desa keberadaan PT. Hutan Ketapang Industri memiliki pendapatan ratarata perbulan sebesar Rp. 9,408,125. Sedangkan Desa Kendawangan Kanan yang tidak berada dilokasi pembangunan PT. Hutan Ketapang Industri memiliki pendapatan rata-rata perbulan sebesar Rp. 7,360,667. Sehingga pendapatan rata-rata perbulan Desa dengan keberadaan PT. Hutan Ketapang Industri dan Desa tanpa keberadaan PT. Hutan Ketapang Industri terdapat selisih atau perbedaan sebesar Rp. 2,047,458. Jadi kesimpulan dari hasil penelitian bahwa Pendapatan Rumah Tangga Masyarakat di Desa Kedondong tergolong tinggi karena melilbihi Upah Minimum Rata-Rata pendpatan yaitu sebesar Rp.1.800.000.

C. Pengaruh Keberadaan PT. Hutan Ketapang Industri terhadap Pendapatan Rumah Tangga Masyarakat Desa Kedondong.

Secara umum dapat diungkapkan bahwa dengan adanya kawasan perkebunan telah menyebabkan munculnya sumber-sumber pendapatan rumah tangga masyarakat baru yang bervariasi. Sebelum dibukanya kawasan PT. Hutan Ketapang Industri di Desa Kedondong, sumber pendapatan rumah tangga masyarakat relative homogen, yakni menggantungkan hidupnya pada sektor primer, memanfaatkan sumberdaya alam yang tersedia seperti apa adanya tanpa penggunaan teknologi yang berarti.

Pembangunan perkebunan Hutan Tanaman Industri PT. Hutan Ketapang Industri mempunyai pengaruh terhadap Pendapatan Rumah Tangga Masyarakat di wilayah perkebunan, yaitu dapat menciptakan lapangan usaha baru seperti:

1. Membukan usaha sembako

2. Membuka Usaha Mebel

3. Membukan Usaha Menjahit

4. Warung Makan

5. Warung Es

6. Kios BBM

Pengembangan perkebunan Hutan Tanaman Industri PT. Hutan Ketapang Industri di pedesaan telah membuka peluang kerja bagi masyarakat. Dengan adanaya perusahaan PT. Hutan Ketapang Industri, mata pencaharian masyarakat Desa Kedondong tidak lagi terbatas pada sektor primer dalam memenuhi kebutuhan keluarganya, tetapi telah memperluas ruang gerak usahanya pada sektor tersier. Pada masyarakat Desa Kedondong khusunya remaja yang tidak melanjutkan pendidikan lebih memilih bekerja di PT. Hutan Ketapang Industri dari pada menganggur. Lain halnya pada masyarakat Desa Kendawangan Kanan khusunya remaja yang tidak melanjutkan pendidikan hanya memilih menganggur dari pada bertani, berkebun dan bekerja sebagai nelayan serta pekerjaan lainnya. 


\section{KESIMPULAN DAN SARAN \\ Kesimpulan}

Berdasarkan uraian hasil penelitian dan untuk menjawab permasalahan dari penelitian ini, maka dapat dikemukakan kesimpulan sebagai berikut :

1. Hutan Tanaman Industri PT. Hutan Ketapang Industri memberikan pengaruh yang terhadap peningkatan pendapatan. Rata-rata Pendapatan Rumah Tangga Masyarakat lebih besar dari pada Pendapatan Rumah Tangga Desa Kendawangan Kanan.

2. Aktifitas Hutan Tanaman Industri memberikan pengaruh yang cukup besar terhadap peningkatan Pendapatan Rumah Tangga Masyarakat di Desa Saran Kedondong Kecamatan Kendawangan Kabupaten Ketapang.

Berdasarkan data dan pembahasan pada bab-bab sebelumnya maka pada tulisan ini penulis menyarankan hal-hal sebagai berikut :

1. Hendaknya memberdayakan seluruh Instansi, lembaga maupun NGO yang berhubungan dengan kegiatan dimaksud. Tatanan administrasi dan kinerja para aparatur pemerintahan harus diperbaiki mulai dari tingkatan paling bawah hingga ketingkatan tertinggi yang memiliki wewenang untuk mengeluarkan izin usaha. Pengusaha dan masyarakat dalam hal ini tidak dapat disalahkan kaena sebelum izin usaha yang dikeluarkan kepada pengusaha telah dilakukan perivikasi atau peninjauan lahan yang akan diberikan kepada pengusaha oleh pejabat pemerintah dari tingkat desa hingga kementerian kehutanan.

2. Diharapkan untuk lebih meningkatkan penyaluran CSR (Corporate Social Responsibility) dari perusahaan terhadap masyakat sekitar wilayan PT. Hutan Ketapang Industri.

3. Percepatan perkembangan daerah setempat diharapkan para pengusaha tidak mengabaikan tujuannya hanya karena mengambil dan menggali potensi yang ada pada daerah tersebut untuk memperoleh keuntungan yang sebesarbesarnya tanpa peduli terhadap perkembangan dan kemajuan daerah setempat.

4. Sebagian besar dampak ekologi yang muncul akibat pengembangan Hutan Tanaman Industri bila terkelola dan terorganisir dengan baik dapat diminimalisir karena para pengusaha Hutan Tanaman Industri telah memikirkan dan melakukan program yang telah terperinci dan terencana dalam mengatasi masalah ekologi atau lingkungan. Namun tidak jarang dampak ekologi ini masih terjadi namun sifatnya hanya sebatas lokal. Tetapi tetap saja akan menimbulkan dampak terhadap lingkungan masyarakat sekitar antara lain : Pencemaran baik melalui udara, air dan tanah akibat Industri pengelolaan hasil Hutan Tanaman Industri, Musnahnya beberapa komponen penyusun ekologi akibat penanaman tanaman yang sejenis (Homogen).

5. Perlu dilakukan kajian terhadap pola pelaksanaan Hutan Tanaman Industri di tahun-tahun mendatang, dengan cara melakukan monitoring dan evaluasi yang melibatkan pihak-pihak independent.

6. Harus dilakukan sosialisasi yang berkelanjutan setelah Hutan Tanaman Industri dilaksanakan, jadi tidak hanya bersifat sementara. 


\section{DAFTAR PUSTAKA}

Adinugroho, W,C, dan Suryadiputra,I,N,N, 2003, Kebakaran Hutan dan Lahan,Seri Pengelolaan Hutan dan Lahan Gambut, Wetlands International-Indonesia Programme, Bogor.

Ali, Faried. 1997. Metodologi Penelitian Sosial Dalam Bidang Ilmu Administrasi. PT. Raja Grafindo Persada. Jakarta.

Ananta, A, 1990, Ekonomi Sumber Daya Manusia, Lembaga Demografi Fakultas Ekonomi Universitas Indonesia, Jakarta.

Anonim 2013. Karyawan dan Harian Lepas Lapangan PT. Hutan Ketapang Industri. Kantor PT. Hutan Ketapang Industri. Ketapang

Anwar, A, 2002, Peranan Pengembangan Ekonomi Komunitas (community economic development) sebagai Komplemen Terhadap Ekonomi Pasar dan Ekonomi Publik. Makalah Panduan Bagi Mahasiswa S3 Ps PWD, IPB, Bogor.

Arisman, H, 2006, Hutan tanaman Industri (HTI) Pemasok Kayu Berkelanjutan bagi Industri Pulp : Pengalaman dan Pengembangan, Makalah disampaikan pada Seminar Kebijakan Pengembangan HTI dan Industri Pulp di Indonesia,tanggal 28 Juni 2008, di Jakarta.

Asosiasi Pulp dan Kertas Indonesia (APKI), 2006, Prospek Industri Pulp dan Kertas di Indonesia, Makalah disampaikan pada Seminar Kebijakan Pengembangan HTI dan Industri Pulp di Indonesia,tanggal 28 Juni 2008, di Jakarta.

Bahua Ikbal Mohamad. 2013. Kontribusi Pendapatan Agribisnis Kelapa pada Pendapatan Keluarga Petani Di Kabupaten Gorontalo. Program Studi Agroteknologi. Fakultas Ilmu Pertanian. Universitas Negeri Gorontalo.

Bishop C.E dan Tousaint W.D, 1982. Pengantar Analisis Ekonomi Pertanian, Jakarta.

BPPHP Wilayah X, 2011, Statistik BPPHP Wilayah X Tahun 2011, BPPHP Pontianak.

BPS Ketapang, 2013. Kecamatan Kendawangan Dalam Angka tahun 2013, BPS Ketapang.

Departemen Kehutanan, 2007, Keputusan Menteri Kehutanan Nomor : SK 220/Menhut-II/2007 tentang Pemberian IUPHHK kepada PT. Sari Bumi Kusuma di Kabupaten Pontianak, Jakarta.

Departemen Kehutanan, 2008, Keputusan Menteri Kehutanan Nomor: P.62/Menhut-II/2008 tentang Rencana Kerja Tahunan Usaha Pemanfaatan Hasil Hutan Kayu pada Hutan Tanaman, Jakarta.

Departemen Tenaga Kerja dan Transmigrasi, 2004, Peraturan Menteri Tenaga Kerja dan Transmigrasi Nomor : Kep. 100/MEN/VI/2004 tentang Ketentuan Pelaksanaan Perjanjian Kerja Waktu Tertentu, Jakarta.

Desa Kedondong, 2007, Data Potensi Desa Kedondong, Kantor Kepala Desa Kedondong.

Desa Kedondong, 2007, Profil Desa Kedondong, Kantor Kepala Desa Kedondong.

Desa Kedondong, 2011, Data Potensi Desa Kedondong, Kantor Kepala Desa Kedondong.

Desa Kedondong, 2011, Profil Desa Kedondong, Kantor Kepala Desa Kedondong. 
Desa Kedondong, 2012, Data Potensi Desa Kedondong, Kantor Kepala Desa Kedondong.

Desa Kedondong, 2015, Data Potensi Desa Kedondong, Kantor Kepala Desa Kedondong.

Djanimar, D, 1996. Kegiatan Industri dan Kertas Serta Dampak terhadap Sosial Ekonomi Kecamatan Siak Sri Indapura Propinsi Riau. Universitas Sumatera Utara, Medan.

Faisal, N, 2007. Pengaruh PT. Toba Pulp Lestari Tbk Terhadap Sosial Ekonomi Masyarakat Porsea, Tesis Pasca Sarjana Program Studi Pengelolaan Sumber Daya Alam, Universitas Sumatera Utara, Medan.

Gilarso, T, 1992, Pengantar Ilmu Ekonomi Makro, Kanisius, Yogyakarta.

Hadi, Sudharto P, 1995, Aspek Sosial Amdal, Gadjah Mada Press University Press, Yogyakarta.

Husin, Umar, 2001, Metode Penelitian untuk skripsi dan tesis bisnis, PT. Raja Grafindo Persada, Jakarta.

Ibrahim, I, 2011. Sistem Silvikultur : Tebang Habis Permudaan Buatan (THPB), http://greendom-afc.blogspot.com/2011/11/sistem-silvikultur-tebang -habisdengan html.

Imbiri S, dkk, 2010. Analisis Dampak PIR Kelapa Sawit Terhadap Kesejahteraan Masyarakat Sekitar di Kabupaten Manokwari (Studi kasus pada petani peserta plasma asal suku Arfak di Distrik Prafi), Jurnal Agritek Vol 18 No.2, April 2010.

Kecamatan Kendawangan, 2013, Profil Desa Kendawangan Kanan. Kantor Kantor Camat Kendawangan.

Kusmantoro, 2019. Analisis Keberagaman Usaha Rumah Tangga Pertanian Lahan Kering di Kabupaten Banyumas Jurnal, Vol.3 No.3 November 2009.

Oka Adnyana Made Dan Suhaeti Nur Rita, 2000. Penerapan Indeks Gini Untuk Mengidentifikasi Tingkat Pemerataan Pendapatan Dan Pengeluaran Rumah Tangga Pedesaan Di Wilayah Jawa Dan Bali. Puslitbang Sosek, Departemen Pertanian, Bogor.

Pahrezza Alif. 2014. Studi Tentang Keberadaan Perkebunan Kelapa Sawit Terhadap Kondisi Sosial Ekonomi Masyarakat Di Desa Pait Kecamatan Long Ikis. Jurnal Ilmu Pemerintahan. Vol 2 no.2. 2014. Jurusan Ilmu Sosial dan Ilmu Politik Universitas Mulawarman.

PT. Hutan Ketapang Industri, 2010, Rencana Kerja Tahunan Usaha Pemanfaatan Hasil Hutan Kayu Pada Tanaman Industri Tahun 2010. Ketapang

Puskesmas Sungai Desa Kedondong, 2014, Data Penderita Penyakit Tahun 2012, Desa Kedondong.

Rahmawati Awalia Diah. 2012. Upaya Peningkatan Pendapatan Petani Melalu Penggunaan Pupuk Organik (Studi kasus pada Petani Jagung Di Desa Surabayan, Kecamatan Sukodadi, Kabupaten Lamongan). Prorgam Studi Agribisnis. Fakultas Pertanian. Jurusan Sosial Ekonomi. Universitas Brawijaya. Malang.

Rhukas, A, 1981, Pola Penghasilan dan Pengeluaran Golongan Produsen Padi Sehubungan Dengan Produksi dan Jumlah Pejualan, Disertasi Doktor Pada Instiutut Pertanian Bogor, Bogor

Rusmawardi. 2007. Dampak Berdirinya Perkebunan Kelapa Sawit terhadap Kondisi Ekonomi Masyarakat ( Studi Kasus Pada Desa Kabuau). 
http://eprints.umm.ac.id/9632/1/Dampak_Berdirinya_Perkebunan_Kelapa_S awit.pdf. Diakses pada tanggal 25 November 2014.

Septiasari Isti Melita, Diarta Surya I Ketut, Dewi Komala Ratna. 2013. Perbandingan Antara Pendapatan Rumah Tangga Petani di Subak Daerah Pariwisata dan Non Pariwisata. E-Jurnal Agribisnis dan Agrowisata. Vol.2, No.4. Program Studi Agribisnis.Fakultas Pertanian.Universitas Udayana.Bali.

Singarimbun, Masri dan Effendi. 1999. Metode Penelitian Survei. Penerbit LP3ES Jakarta.

Soekartawi. 1998. Ilmu Usahatani Dan Penelitian Petani Kecil. Rajawali Press. Jakarta.

Soemitro. 1997. Pendekatan Penyuluhan Pertanian. Dikutip dari Majalah Ekstensia. Volume 5 Tahun IV. Pebruari 1997.

Sugiyono, 2009. Statistika untuk Penelitian. Alfabeta Bandung. Bandung.

Suparmoko, M, 1991. Metode Penelitan Praktis (Untuk Ilmu Sosial dan Ekonomi), BPFE, Yogyakarta

Supriadi Wiwin. 2011. Percepatan Ekonomi Pedesaan Melalui Pembangunan Perkebunan Kelapa Sawit. Program Magister Ilmu Ekonomi. Universitas Tanjungpura Pontianak.

Supriyono, RA. 1998. Manajemen Strategi dan Kebijakan Bisnis. Penerbit BPFE Yogyakarta.

Syahza Almasdi. 2011. Percepatan Ekonomi Pedesaan Melalui Pembangunan Perkebunan Kelapa Sawit. Volume 12, Nomor 2, Desember 2011. Lembaga Penelitian Universitas Riau Kampus Binawidya Km 12,5 Pekanbaru 28293.Indonesia.

Wantasen Erwin, Hartono Budi. 2012. Analisis Faktor-Faktor Yang Mempengaruhi Ekonomi Rumah Tangga Peternak Sapi Peranakan Ongole (PO) Di Kabupaten Minahasa. Fakultas Peternakan Universitas Sam Ratulangi Manado.

Wirosuhardjo, K, 2007, Dasar-Dasar Demografi, Lembaga Penerbit Fakultas Ekonomi UI, Jakarta.

Zein Alfian. 2006. Peningkatan Ekonomi Rumah Tangga Nelayan Melalui Pemberdayaan Wanita Nelayan. Jurnal Mangrove dan Pesisir. Vol.VI No.1/2006. Dosen Fakultal Perikanan Dan Ilmu Kelautan. Universitas Bung Hatta.Padang 